\title{
IMPLEMENTASI PROGRAM SEKOLAH RAMAH ANAK DALAM PROSES PEMBELAJARAN
}

\author{
Agus Fahmi \\ FIPP UNDIKMA \\ Email: fahmi_ap@ikipmataram.ac.id
}

\begin{abstract}
There were 241 cases of violence against children recorded until November 10th 2020. The Office of Women's Empowerment and Child Protection of NTB Province carries out its obligations to protect and fulfill children's rights by trying to protect, save, and provide protection to children from discrimination, violence, and ensuring their right to grow and develop. The government then initiates and runs the Child Friendly School Program. Facts in the field based on initial observations, at State Elementary School 8 Sokong has implemented a child-friendly school program which is becoming an example for other schools. The objectives of this study are (1) to describe the planning for the implementation of the child-friendly school program, (2) to describe the implementation of the Child Friendly School Program, (3) To describe the results of the monitoring and evaluation of the implementation of the Child Friendly School Program at State Elementary School 8 Sokong.This study is a descriptive qualitative research. The data collection used are observation, interview, and documentation. The data obtained validated using source triangulation. The data then analyzed since the data collected, namely data reduction, data presentation, and drawing conclusions and verification. The results of the research show that (1) The Child Friendly School Program planning has fulfilled the program SOP, namely by forming a development team who construct program activity plan. (2) The program implementation has met the program indicators by being implemented without violence and discrimination against child. (3) Monitoring is carried out by providing previously prepared questionnaires to be filled out by school principals and representatives of educators and education staff, then monitored by relevant agencies and institutions. Meanwhile, the evaluation of the program implemented at State Elementary School 8 Sokong was evaluated in its entirety along with other programs.
\end{abstract}

Keywords: Child-friendly School, Learning.

Abstrak: Tercatat 241 data kasus mengenai kekerasan terhadap anak. Dinas Pemeberdayaan Perempuan, Perlindungan Anak (DP3A) NTB hinggak tanggal 10 november 2020. Dinas Pemeberdayaan Perempuan, Perlindungan Anak menjalankan kewajibannya untuk melindungi serta memenuhi hak-hak anak dengan berusaha menjaga, menyelamatkan serta memberi perlindungan kepada anak dari diskriminasi, tindak kekerasan, dan memiliki hak untuk tumbuh dan berkembang. Sehingga pemerintah menyusun dan merealisasikan program Sekolah Ramah Anak. Fakta di lapangan berdasarkan observasi awal, di SDN 8 Sokong telah menerapkan program sekolah ramah anak yang mana menjadi contoh untuk sekolah lain.Tujuan penelitian ini adalah (1) Untuk Mendeskripsikan Perencanaan Implementasi Program Sekolah Ramah Anak di SDN 8 Sokong, (2) Untuk Mendeskripsikan Pelaksanaan Implementasi Program Sekolah Ramah Anak di SDN 8 Sokong, (3) Untuk Mendeskripsikan Hasil Monitoring Dan Evaluasi Implementasi Program Sekolah Ramah Anak di SDN 8 Sokong, Penelitian ini menggunakan pendekatan kualitatf dengan metode deskriptif. Pengumpulan data yang digunakan yaitu teknik observasi, wawancara,dan dokumentasi. Keabsahan data dalam penelitian ini menggunakan triangulasi sumber. Analisis data dalam penelitian ini dengan menggunakan pengumpulan data, reduksi data, penyajian data, serta menarik kesimpulan dan verifikasi.Hasil penelitian di SDN 8 Sokong yaitu bahwa (1) Perencanaan program SRA telah memenuhi SOP program SRA dengan membentuk tim pengembangan SRA yang kemudian membuat rencana kegiatan program SRA.(2) Pelaksanaan program SRA telah memenuhi indikator SRA dengan dilaksanakan tanpa adanya kekerasan dan diskriminasi kepada anak. (3) Monitoring yang dilakukan dengan memberikan kuisioner yang disusun sebelumnya untuk diisi oleh kepala sekolah dan wakil dari pendidik dan tenaga kependidikan, kemudian dipantau oleh dinas dan lembaga terkait. Sedangkan evaluasi program SRA yang diterapkan di SDN 8 Sokong dievaluasi keseluruhan bersamaan dengan program lain.

Kata Kunci: Sekolah, Ramah Anak, Pembelajaran 


\section{PENDAHULUAN}

Pendidikan merupakan hak asasi manusia setiap warga negara Indonesia, oleh karna itu setiap warga berhak memperoleh pendidikan sesuai dengan minat dan bakat yang dimilikinya tanpa memandang status sosial, status ekonomi, suku, etnis, agama, dan gender. Sebagaimana yang telah dituliskan dalam Perundang-undangan Nomor. 23 tahun 2002 tentang perlindungan anak. Hal tersebut berusaha menjaga, menyelamatakan serta memberi perlindungan kapada anak dari tindak kekerasan, anak memiliki hak hidup, tumbuh dan berkembang, serta adanya perlindungan anak dari diskriminasi dan kekerasan fisik atau non fisik.

Kebijakan program sekolah ramah anak yang selanjutnya di singkat menjadi SRA merupakan salah satu kebijakan pemerintah yang di keluarkan melalui peraturan kementerian pemberdayaan perempuan dan perlindungan anak repubik indonesia (Kemen PPPA) No. 8 Tahun 2014 Tentang Kebijakan Sekolah Ramah Anak (SRA).

Kebijakan ini dikeluarkan agar anak merasa aman dan terlindungi dari kekerasan dalam dunia pendidikan khususya di sekolah. Dalam Permen PPPA pasal 1 dijelaskan bahwa, sekolah ramah anak selanjutnya disingkat SRA adalah suatu pendidikan formal, nonformal dan informal yanag aman, bersih, dan sehat peduli dan berbudaya lingkungan hidup, mampu menjamin, memenuhi,menghargai hak-hak anak dan perlidungan anak dari kekerasan, dan perlakuan salah lainnya serta mendukung partipasi anak dalam perencanaan, kebijakan, pembelajaran, pengawasan, dan mekanisme pengaduan terkait pemenuhan hak dan peralindungan anak di pendidikan.

Dalam UU No. 20 Tahun 2003 Tentang Pendidikan Nasional dan Perinsip Perlindungan Anak. Pendidikan diselengrakan secara demokratis dan berkeadilan serta tidak diskriminasi dengan menjunjung tinggi hak asasi manusia, nilai, keagamaan, nilai kultural dan kemajemukan bangsa. Guna terlaksananya pendidikan ramah anak di satuan pendidikan, maka harus memeiliki perinsip perlindungan anak: tanpa kekerasan, tanpa diskriminasi, kepentingan terbaik bagi anak, hak tumbuh dan berkembang serta penghargaan terhadap pendapat anak.

Adapun pengertian anak itu sendiri sebagaimana tertuang dalam Undang-Undang No.23 Tahun 2002 pasal 1 tentang perlindungan anak, anak didefinisikan sebagai seseorang yang belum berusia 18 (delapan belas) tahun, termasuk anak yang masih dalam kandungan. Baik anak dan orang berpartisipasi serta mendapatkan perlindungan dari tindakan kekerasan dan baik di dalam dunia pendidikan ataupun lingkungan sekitarnya.

Tujuan dari dikeluarkanya kebijakan program sekolah ramah anak (SRA) adalah memenuhi, menjamin, dan melindungi anak-anak melalui sekolah ramah anak,serta memastikan bahwa suatu pendidikan mengembangkan minat, bakat, dan kemamapuan anak, dewasa dapat tumbuh dan mengembangkan potensi dirinya secara oftimal jauh dari ketakutan akan kekerasan. Negara berkewajiban memenuhi hak anak atas kelangsungan hidup, tumbuh dan berkembang.

Menurut Muhammad Yaumi (2014:14) mengatakan bahwa "kekerasan guru terhadapa murid dapat ditinjau dari empat dimensi, yaitu: (1) kekerasan verbal (2) kekerasan fisik (3) kekrasan psilologis, dan (4) kekerasana profesionalisme". Kekerasan verbal mencangkup penggunaan stereotipe dan penamaan bermuatan seks, rasis, kultur, ekonomi, ketidak sempurnaan pisik dan hormofibik. Kekerasan fisik meliputi mendorong, mencubit, menjambak, menjewer, memukul dengan penggaris atau melempar sesuatu. Kekerasan 
psikologis terjadi melalui tindakan berteriak, berbicara dengan kasar, menyobek hasil kerja, mengadu domba siswa dan membuat ancaman.

Adapun kekerasan yang berkaitan dengan profesionalisme dapat terjadi melalui penilaian yang tidak adil, menerapkan hukuman dengan pilih kasih, melakukan cara-cara pendisiplinan yang tidak pantas, mengarahakan pada kegagalan dengan menetapkan standar tidak wajar bagi siswa.

Berdasarkan data yanag dirilis oleh Dinas Pemeberdayaan Perempuan, Perlindungan Anak (DP3A) NTB hinggak tanggal 10 november 2020 tercatat jumlah kekerasan terhadap anak sebanyak 241 kasus yang tersebar sepuluh kabupaten/kota. Paling tinggi kasus kekerasan anak terjadi di Kabupaten Lombok Utara sebanyak 51 kasus. Rinciannya bentuk kekerasan fisik sebanyak 8 kasus, psikis 4 kasus, kekerasan seksual 8 kasus, pelantaran anak 4 kasus dan lain-lain 27 kasus.

Kemudian di Lombok Timur jumlah kasus kekerasan terdapat anak sebanyak 43 kasus, yang dimana terdiri dari kekerasan fisik 3 kasus, psikis 2 kasus, kekerasan seksual 15 kasus, pelantaran anak 4 kasus, dan lainya 19 kasus. Kabupaten Sumbawa kasus kekerasan anak sebanyak 40 kasus, terdiri dari kekerasan fisisk 15 kasus dan kekerasan seksual 25 kasus. Kabupaten Dompu kekerasan anak sebanyak 24 kasus, terdiri dari kekerasan fisik 3 kasus, psikis 3 kasus, seksual 14 kasus, eksploitasi 1 kasus dan pelantaran anak 3 kasus.

Adapun PERDA Kabupaten Lombok Utara No.1 tahun 2017 tentang penyelenggaran perlindungan perempuan dan anak. Dengan memperhatikan agama, adat istiadat, sosial budaya masyarakat. Hal tersebut dapat dilakukan salah satunya melalui lembaga pendidikan dengan mengedepankan perinsip dasar hak perlindungan perempuan dan anak meliputi: nondiskriminasi, kepentingan terbaik bagi perempuan dan ank, hak untuk hidup, kelangsungan hidup dan berkembang, penghargaan terhadap pendapat anak, kearipan lokal dan tranparansi.

Sebagaimana dalam Peraturan Bupati Lombok Utara tahun 2015 Tentang Pengembangan Kabupaten Layak Anak (KLA). Lembaga pendidikan memastikan anak mendapatkan akses pendidikan dan pelatihan yang berkualitas tanpa diskriminasi, mendorong terciptanya sekolah ramah dengan mengaplikasikan konsep disiplin tanpa kekerasan, menjamin keamanan dan keselamatan anak.

Berdasarkan kondisi yang diuraikan peneliti di atas , maka peneliti tertarik untuk melakukan penelitian terkait dengan. Implementasi Program Sekolah Ramah Anak Dalam Mewujudkan Proses pembelajaran Ramah Anak di SDN 8 Sokong Tanjung Kabupaten Lombok Utara.

\section{METODE PENELITIAN}

Jenis penelitian yang digunakan dalam penelitian ini adalah jenis penelitian kualitatif. Sumber data yang digunakan dalam penelitian ini adalah sumber data primer dan sumber data sekunder. Meotde pengumpulan data dalam penelitian ini adalah observasi, wawancara, serta metode dokumentasi. Analisis data yang digunakan dalam penelitian ini adalah analisis data oleh Miles dan Huberman.

HASIL DAN PEMBAHASAN

Perencanaan Implementasi Program Sekolah Ramah Anak di Sekolah Dasar Negeri 8 Sokong. 
Pengembangan kebijakan program SRA diawali dengan adanya perencanaan. Menurut Berger dalam Morissan menjeskan bahwa perencanaan merupakan representatif kognitif secara berurutan dari tindakan yang diarahkan pada tujuan. Dengan kata lain perencanaan adalah gambaran mental dengan langkah-langkah berurutan yang ditempuh seseorang untuk mencapai sebuah tujuan. Langkah tindakan tertentu dilaksanakan diawal agar tindakan lainnya dapat dilakukan, sehingga perencanaan adalah proses memikirkan berbagai rencana tindakan.

Hafid Setiadi menjelaskan perencanaan adalah upaya dengan sebuah prosedur yang terangkai secala logis sehingga dapat menjelaskan tahapan yang harus dilalui untuk mencapai sebuah tujuan.Hal tersebut seperti yang dijelaskan dalam temuan penelitian mengenai perencanaan program SRA di SDN 8 Sokong berikut : (1). Perencanaan program SRA di SDN Sokong diawali dengan adanya rapat antara Kepala Sekolah dengan komite serta staff terkait Program SRA dengan Dinas Kependidikan Pemuda dan Olahraga Kabupaten Lombok Utra rapat tersebutmembahas perencanaan hingga evaluasi program SRA. (2). SDN 8 Sokong mengajukan portofolio Sekolah Ramah Anak terhadap pihak terkait, kemudian portofolio yang diajukan di cek dan dilakukan visitasi ke sekolah dari pihak terkait. Kemudian pihak terkait menentukan kelayakan sekolah. (3). Pimpinan serta komite sekolah membentuk tim pengembangan SRA dalam tim pengembangan juga adanya keterlibatan siswa. (4). Kemudian tim pengembangan menyusun rencana tahunan yang terintregasi dengan kebijakan program SRA, kesehatan sekolah, sekolah aman bencana.

Perencanaan program SRA diawali dengan kemunculan masalah-masalah mengenai hak-hak anakyangsemakin meresahkan dan butuh penyelessaian, hingga penyusunan atau perencanaaan SRA diharapkan mampu dijadikan solusi dari masalah-masalah tentang pemenuhan hak anak terutama di lingkungan sekolah.

Berbagai perencanaan yang telah disusun kemudian dituangkan dalam alternatif kebijakan yang didalamnya terdapat panduan-panduan untuk mengembangkan program dan kegiatan perlindungan dan pendidikan anak yang berujung pada SRA.Alternatif kebijakan dalam bentuk program SRA kemudian dikaji untuk dilihat manfaatnya ketika diimplementasikan. Program SRA yang diajukantidak diambil begitu saja sesuai rumusan yang ada, tetapi perlu diperoleh dukungan dari berbagai pihak yang relevan.

Perencanaan adalah sesuatu yang terdapat dalam pikiran dan kemudian disusun dalam suatu tindakan, sebagaimana yang disimpulkan Friedman dalam jurnal perencanaan Wilayah dan Kota oleh Agustomi bahwa perencanaan adalah usaha untuk menghubungkan pengetahuan ilmiah dan teknis terhadap tindakan-tindakan.

\section{Pelaksanaan Implementasi Program Sekolah Ramah Anak di Sekolah Dasar Negeri 8 Sokong.}

Pelaksanaan implementasi merupakan suatu proses yang membicarakan penerapan program yang bersifat sosial atau dalam duniapendidikan. Implementasi program yaitu langkah-langkah pelaksanaan suatu kegiatan dalam upaya untuk mencapai tujuan dari program tersebut.

Teori implementasi program oleh Charles O. Jones dalam jurnal moral dan kewarganegaraan oleh Fadhila Shofiana menjelaskan program merupakan salah satu komponen dalam suatu kebijakan untuk mencapai tujuan. Terdapat tiga dasar dalam mengoperasikan program, yaitu: (1) pengorganisasian, dibutuhkan struktur organisasi yang 
jelas sehingga tenaga pelaksana terbentuk dari sumber daya manusia yang kompeten dan berkualitas; (2) interpretasi, yang dilakukan para pelaksana untuk menerapkan program yang sesuai dengan petunjuk teknis dan petunjuk pelaksana agar tujuan yang diharapkan dapat tercapai; (3) penerapan atau aplikasi, perlu adanya pembuatan prosedur kerja yang jelas agar program kerja dapat berjalan sesuai dengan jadwal kegiatan sehingga tidak berbenturan dengan program yang lain. Sehingga tahap-tahap implementasi kebijakan yang diterapkan di SDN Sokong, yaitu :

Tahap pengorganisasian diawali dengan penyusunan tim pelaksana dan tim pengembangan SRA yang ditetapkan dalam surat keputusan tentang pengembangan SDN Sokong yang ditetapkan pada 20 mei 2020 oleh Adnan Muktamar, S.Pd, M.Pd selaku penanggung jawab program SRA di SDN Sokong. Kebutuhan sarana dan prasarana untuk memenuhi keterlaksanaan program SRA di SDN 8 Sokong telah terpenuhi dengan adanya kantin sehat, program UKS, program Adiwiyata, toilet dan kamar mandi terpisah antara lakilaki dan perempuan.Tahap interpretasi, yaitu tahap untuk menguraikan suatu program yang sesuai dengan petunjuk teknis. Sehingga dapat dimengerti oleh pelaksana dan sasaran program. Sebagaimana SDN 8 Sokong dalam penerapan program SRA dengan adanya komitmen yang disetujui atau dipahami oleh seluruh warga sekolah. Selain itu terdapat prosedur teknis kegiatan yang ramah anak.

BerdasarkanPermen PPPA No.8 tahun 2014 Tentang Kebijakan Sekolah Ramah Anak. Ada beberapa indikator Sekolah Ramah Anak (SRA) sebagai berikut: (1). Kebijakan sekolah ramah anak, (2). Pelaksanaan Kurikulum, (3). Pendidik dan tenaga kependidikan terlatih hakhak anak (4). Sarana dan prasarana sekolah ramah anak, (5). Partisipasi anak, (6). Partisipasi orang tua, lembaga masyarakat, dunia usaha, pemangku kepentingan lainnya dan alumni.

\section{Pelaksanaan kurikulum di SDN 8 Sokong}

Kurikulum SDN 8 Sokong menggunakan kurikulum strandar nasional pendidikan berupa kurikulum 2013, pendidikan lingkungan hidup atau adiwiyata, pendidikan karakter, dan pendidikan kesehatan atau UKS).Proses belajar mengajar di SDN 8 Sokong dirancang dengan kegiatan menyenangkan dengan kelembutan sikap, memberikan motivasi, menghindari prakonsepsi negatif, mendekatkan diri kepada agama serta mengembangkan pembelajaran yang menfasilitasi keragaman karakter danpotensi peserta didik. Hal tersebut sesuai dengan pemaparan Senowarsito dalam jurnal pendidikan bahwa dalam proses kegiatan belajar mengajar tersebut menggunakan Child Friendly Teaching Model (CFTM) model pembelajaran yang berbasis 3P, provisi, proteksi, dan partisipasi. Dan PAIKEM, pelajaran afektif, inovatif, kreatif, efektif dan menyenangkanPAIKEM, pelajaran afektif, inovatif, kreatif, efektif dan menyenangkan, (Senowasito,2012:44).

Proses pembelajaran di SDN 8 Sokong juga menjamin setiap anak untuk menikmati hak anak untuk pendidikan tanpa diskriminasi berdasarkan disabilitas, gender, suku bangsa, agama, dan latar belakang orang tua. Dalam proses kegiatan belajar mengajar siswa tidak diskriminasikan ke arah negatif. Selain itu adanya pendidikan inklusif yang menampung semua murid di kelas yang sama. SDN 8 Sokong juga membuat program pembelajaran yang layak, menantang, tetapi disesuaikan dengan kemampuan dan kebutuhan setiap murid maupun bantuan dan dukungan yang dapat diberikan oleh para guru, agar anak-anak berhasil.

Model pembelajaran yang berbasis 3P sebagaimana yang di ungkap oleh senowarsito dalam model pembelajran ini sangat tepat di terapkan untuk pendidikan anak kebutuhan dasar 
karna akan lebih terperhatikan. Anak merasa nyaman dan telindungaikarna ancaman dan hukuman jauh dari kehidupan anak. Perkembangan anak lebih maksimal. Akan menjadi lebih berani karena diberi kesempatan untuk berpartisipasi. Seperti yang dilakukan di SDN 8 Sokong pada proses pembelajaran yang menitik beratkan kepada hak setiap anak diantaranya menyatakan dan didengar pendapatnya, menerima, mencari, dan memberikan informasi sesuai dengan tingkat kecerdasan dan usianya demi pengembangan dirinya sesuai dengan nilai-nilai kesusilaan dan kepatutan.

Dengan demikian, indikator pelaksanaan kurikulum dalam rumusan masalah pelaksanaan program SRA di SDN 8Sokong pada pembelajaran yang diterapkan telah sesuai dengan model pembelajaran yang ramah anak dengan penggunaan model pembelajaran Child Friendly Teaching Model (CFTM) yang berbasis pada 3P yaitu Provisi, Proteksi, dan Partisipasi dan PAIKEM, pelajaran afektif, inovatif, kreatif, efektif dan menyenangkan.

\section{Pendidik dan tenaga kependidikan terlatih hak anak di SDN 8 Sokong.}

Pada teori George Edward III menjelaskan bahwa salah satu implementasi program yang efektif dengan adanya Resources berkenaan dengan ketersediaan sumber daya pendukung, khususnya sumber daya manusia. Sumber daya manusia SDN 8 Sokong dalam pengimplementasian program SRA dilihat diukur dengan kualifikasi pendidikan guru SDN 8 Sokong. Tenaga pendidik dan kependidikan yang terdapat di SDN Sokong berjumlah 23 orang. Terdapat 14 guru yang telah menjadi PNS, guru CPNS 1 orang, 8 guru tidak tetap dan 1 satpam dan dengan rata-rata dengan pendidikan terahir S-1. Pelaksanaan kebijakan juga dipengaruhi oleh sumber daya manusia yang harus cukup (jumlah) dan cakap (keahlian). Ketepatan dan kelayakan jumlah staff (sumber daya manusia) dan keahlian harus dimiliki yang sesuai dengan tugas pekerjaan yang ditanganinya.

Jadi dengan demikian indikator pendidik dan tenaga kependidikan pada rumusan masalah pelaksanaan program SRA di SDN 8 Sokong bahwa kelayakan guru di SDN 8 Sokong dilihat dari cara mengajar guru. Hal tersebut dilihat dari tanggapan para siswa mengenai cara mengajar guru yang menyenangkan dan memberikan kebebasan berpendapat serta tidak ada lagi hukuman fisik yang diberikan oleh guru untuk siswa di SDN 8 Sokong.

\section{Sarana dan prasarana SRA di SDN 8 Sokong.}

Teori George Edward III juga menjelaskan bahwa sumber daya dalam bentuk sarana prasarana juga mendukung penerapan program yang efektif.Sumber daya peralatan sebagai sarana dalam pelaksanaan kebijakan yang meliputi gedung, tanah dan sarana lain yang akan memudahkan pelayanan dalam implementasi program. Apabila terdapat keterbatasan fasilitas yang tersedia, maka kurang menunjang efisiensi dan tidak mendorong motivasi para pelaksana dan sasaran program dalam melaksanakan kebijakan.Lingkungan di luar ruangan yang berbasis elektronik lebih disukai oleh anak.

Memperkuat uraian sebelumnya, siswa senang dengan area bermain dan area yang hijau penuh dengan tanaman yang baik untuk kesehatannya. Di SDN 8 Sokong telah memiliki ruang/area lapangan bermain, taman di depan kelas. Sekolah memiliki rambu/tanda/informasi SRA dengan adanya atau papan informasi di lingkungan sekolahmembuata psiswa-siwi mudah mendapatkan informasi petunjuk tempat. SDN 8 sokong memiliki ruang dan program UKS yang telah memenuhi standar minimal kesehatan dengan adanya tempat tidur, wastafel, dan kamar mandi. Selain itu, di dalam UKS juga terdapat ruang diskusi untuk tim kesehatan sekolah berdiskusi, berkoordinasi, atau melakukan 
kegiatan belajar mengenai kesehatan. SDN Model memiliki Kantin sehat yang disebut dengan kantin SEJUKS (sehat, jujur, dan UKS).

\section{Partisipasi anak}

Keterlibatan siswa di sekolah merupakan kualitas dan kuantitas keadaan psikologis siswa seperti reaksi kognitif, emosional dan perilaku terhadap proses pembelajaran, serta kegiatan akademik dan sosial dikelas ataupundiluar kelas untuk mencapai hasil belajar yang baik. Willms juga menambahkan bahwa terlibatnya siswa di sekolah merupakan bagian psikologis mengenai rasa kepemilikan siswa terhadap sekolahnya, menerima nilai-nilai sekolah dan perilaku yang berkaitan dengan partisipasi di sekolah Siswa yang dilibatkan dalam kerjasama membuat lingkungan kelas yang positif. Sejalan dengan ungkapan tersebut maka Keterlibatan siswa dalam menyusun tata tertib kelas maupun tata tertib sekolah. Apabila peserta didik melanggar maka akan dikenai hukuman tetapi bukan hukuman fisik.

Hal tersebut juga dilakukan di SDN 8 Sokong bahwa ketika siswa mendapat hukuman, hukuman yang didapatkan tidak hukuman fisik tetapi kepada hukuman yang lebih mendidik, seperti menulis hal yang diperintahan guru.Dengan demikian indikator partisipasi anak pada rumusan masalah pelaksanaan implementasi program SRA di SDN 8 Sokong dipaparkan bahwa siswa terlibat dalam segala kegiatan yang dilakukan di sekolah. Siswa selalu aktif dalam kegiatan pembelajaran di luar maupun di dalam ruangan. Siswa juga memberikan penilaian terhadap kondisi sekolah. Misalkan dalam masalah lingkungan siswa memberikan tanda pada tempat-tempat yang dianggap memiliki potensi dan resiko, selain itu siswa dilatih untuk beranimenyampaikan pendapat baik melalui kegiatan formal, pembelajaran atau pada saat event-event besar.

Partisipasi orang tua, masyarakat, dunia usaha, pemangku kepentingan, dan lain sebagainya.

Hubungan orangtua dengan anak yang positif memiliki pengaruh pada anak ketika di sekolah. Sehingga baik dan buruknya perilaku anak di sekolah cenderung dipengaruhi oleh kebiasaan yang dilihat dan diterima anak di sekitar lingkungannya, terutama di rumah sebagai pendidikan pertama bagi anak. Sejalan dengan uraian tersebut maka anak membutuhkan orang tua untuk memberikan pengetahuan tentang bagaimana cara berinteraksi dengan orang lain maupun dengan lingkungan. Sebagaimana yang dilakukanorang tuawali murid SDN 8 Sokong yang menyediakan waktu rutin sekurang-kurangnya 15 (lima belas) menit sehari untuk mendengarkan dan menanggapi curhat anak dan mendampingi anak belajar guru perlu mengajak orangtua untuk kegiatan yang dilakukan di sekolah, seperti diskusi pembuatan fasilitas belajar peserta didik, diskusi tentang kemajuan belajar peserta didik, dan sebagainya. Seperti yang dilakukan di SDN 8 Sokog, Orang tua aktif mengikuti pertemuan koordinasi penyelenggaraan SRA serta melakukan komunikasi intens antara orang tuadengan guru.

Seperti yang Preston sebutkan bahwa masyarakat terlibat dalam komunitas sekolah (School Community Council-SSC) biasa terlibat langsung dan tidak langsung. Terlibat langsung karena mereka adalah bagian dari anggota komunitas sekolah, dan yang tidak terlibat langsung adalah simpatisan masyarakat.Keluarga dan masyarakat memiliki peran penting dalam kelangsungan hidup anak. Sehingga untuk meminimalisir perilaku menyimpang yang dilakukan oleh anak di sekolah, pihak sekolah perlu bekerjasama dengan orang tua untuk membentuk suasana yang positif. Menghargai pendapat orang tua siswa, orang tua terlibat aktif dalam pengembangan keterampilan emosional, serta perlu membekali anak dengan keterampilan sosial. 


\section{KESIMPULAN}

Adapun kesimpulan yang diambil adalah: Perencanaan yang dilakuka di SDN 8 Sokong telah meenuhi standar operasional prosedur program SRA.Implementasi Sekolah Ramah Anak di SDN 8 Sokong telah diterapkan dengan sudah cukup baik dan sudah memenuhi indikator SRA Kurikulum yang diterapkan di SDN 8 Sokong yang telah diintegrasikan dengan program SRA yang tidak terdapat diskriminasi dan kekerasan kepada anak.Hasil Monitoring atau evaluasi program Sekolah Ramah Anak (SRA) yang dilakukan di SDN 8 Sokong dilakukan dengan memberikan kuisioner yang disusun sebelumnya untuk diisi oleh kepala sekolah dan wakil dari pendidik dan tenaga kependidikan, kemudian dipantau oleh dinas dan lembaga terkait. Sementara evaluasi program Sekolah Ramah Anak (SRA) yang diterapkan di SDN 8 Sokong dievaluasi keseluruhan bersmaan dengan program lain.

\section{DAFTAR PUSTAKA}

Arikunto, Suharsini. Prosedur Penelitian Kualitatif Suatu Penedekatan Praktik, Jakrta: Pt Rinerka Cipra, 2010.

Arikunto, Suharsisni. Evaluasi Program Pendidikan, Jakarta: Bumi Aksara, 2010.

Alifudin, Moh. Kebijakan Pendidikan Formal, Jakarta: Magnascript Publising, 2011.

Emzir, Metodologi Penelitian Kualitatif: Analisis Data, Jakarta: PT. Raja Grapindo Persada, 2010.

Guawan, Imam. Metode Penelitian kualitatif, Teori dan Praktik. Jakarta: Bumi Aksara, 2015.

Hamalik, Oemar. Psikologo Belajar dan Mengajar, Bandung: Sinar Baru Algesido, 2012.

IKIP MATARAM. 2011. Pedoman Pembimbingan Dan Penulisan Karya Ilmiah. IKIPMATAM

Kasus Kekerasan Anak, Terbanyak di KLU, (Online).

http://radarlombok.co.id/214-kasus kekerasan-anak-terbanyak-di-klu.html.diakses pada 28

November 2020 pukul 22:18

Kusnadi. 13 bangunan sekolah ramah anak untuk KLU. Mc Prov Nusa Tenggara Barat, 2019. http://infopublik.id/kategori/nusantara/340322/13-bangunan-sekolah-bambu-ramahanak-untuk-klu.di akses pada 29 November 2020 pukul 17:45

Undang-Undang Republik Indonesia No. 23 tahun 2002 Tentang Perlindungan Anak.

Kristanto, Ismatul Khasanah, Mila Karmila, “ Identifikasi Model Sekolah Ramah Anak ( SRA) Jenjang Satuan Pendidikan Anak Usia Dini.” Jurnal Penelitian Paudia. Vol.1, November 2011, hal. 43.

Moleong, Lexy J. Metode Penelitan Kualitatif, Bandung: PT. Remja Rosdakarya, 2014.

Mahmud, Metode Penelitian Pendidikan, Bandung: CV Pustaka Setia, 2011.

Muhdi, Senowarsito, Listianing S, "Pendidikan Kecakapan Hidup (Life Skills) Melalui Child Friendly Teaching Model (CFTM) Sebagai Dasar Membangun Karakter Siswa”, EDimas ( Jurnal Pengabdian Kepada Masyarakat), Vol. 3 , No.1, September 2012. hlm. 43.

Galuh Mentari Putri. Implementasi Sekolah Ramah Anak Di Sekolah Dasar Negri Model Kota Malang.2020. http:/entheses .uin-malang.ac.id. di akses 16 mei 2021

Prasetiawan, Hardi. "Peran Bimbingan Konseling Dalam Penididkan Ramah Anak", Jurnal Care (Children Advisiory, Research, And Education). Vol.4, Nomor 1, juli 2016, hal, 57. 
Permen Pemberdayan Perempuan dan Perlindungan anak Republik Indonesia No. 8. Tahun 2014 Tentang Kebijakan Sekolah Ramah Anak.

Risminawati, Siti Nur RoPifi'ah, "Implementasi Pendidikan Ramah Anak", Profesi Pendidikan Dasar, Vol.2. Nomor 1, Juli 2015, hlm,72.

Sugiyono, Metode Penelitian Pendidikan (Pendekatan Kuantitatif, Kualitatif, Dan R\&D, Bandung: Alfabeta,2017.

Sukamadinata, Nana Syaodih. Metode Penelitian Pendidikan, Bandung: Remaja Rosdakarya, 2011.

Sutisno Rawita, Ino. Kebijakn Pendidikan: Teori, Implementasi, dan Monev, Yogyakarta: Kurinia Kalam Semesta, 2013.

Subarsono, AG. Analisis kebijaka Publik: Konsep Teori Dan Aplikasi. Yogyakarta: Purtaka Pelajar, 2016.

Supardi. Bacaan Cerdas Menyusun Skrkipsi, Yogyakarta: Kurnia Kalam Semesta Alam, 2011.

Sholeh Ni'am, A. Panduan Sekolah \& Madrasah Ramah Anak, Jakarta: Erlangga, 2016.

Setiadi, Hafid. (2014). Dasar-dasar Perencanaan. Jakrta: universitas terbuka.

Sofiana Fadila, kajian moral dan kewarganegaraan, volume 07 nomor 02 tahun 2019,646660.

Undang-undang Perlindungan anak ( UU RI No. 23 Th, 2002), Jakarta: Sinar Grapika, 2011.

Yaumi, Muhammad. Pendidikan Karakter, Landasan, Pilar, dan Implementasi. Jakarta: Prenadamedia Grup, 2014.

Yulianto, Aguis. "Pendidikan Ramah Anak: Studi Kasus SDIT Nur Hidayah surakarta", AtTarbawi, vol. Nomor 2, Juli-Desember, 2016, hlm, 134.

Zaenuddin. Implementasi Program Sekolah Anak, Studi Kasus pada Sekolah Dasar Ampenan Kota Mataram, Tahun, 2018. https://docplayer.info/171153358-Implementasiprogram-sekolah-ramah-anak-sra-studi-kasus-pada-sd-negeri-1-ampenan-kotamataramh tml di akses 29 November 2020 Pukul: 08:34 WIB. 